\title{
DESIGN OF A HORIZONTAL ANAEROBIC REACTOR
}

\author{
Mónika BAKOSNÉ DIÓSZEGI \\ Óbuda University, Bánki Donát Faculty of Mechanical and Safety Engineering, Budapest, Hungary, \\ dioszegi.monika@bgk.uni-obuda.hu
}

\begin{abstract}
The economics of biogas plants have an impact on the justification of the industrial unit. The conditions of high-yielding high-quality biogas production are estimated on the basis of laboratory fermentation studies. In designing the laboratory fermenters, working conditions must be modelled. However, the biggest problem with the biological model is its size, because the magnitude is less than in industrial applications and therefore extremely sensitive to environmental influences. During the design, an important aspect is that the periodic mixing of the raw material can be done in the reactors as in the industry. This article shows the equipment based on empirical research.
\end{abstract}

Keywords: mixing, anaerobic fermentation, design, implementation.

\section{Introduction}

In the biogas laboratory of Óbuda University, vertical batch systems are used, characterized by mixed and unmixed designs. During the batch process, all the ingredients are fed into the reactor simultaneously. Subsequently, neither feeding nor taking of material occurs within the system. The gas formation starts slowly and then continues to grow, eventually decreases and stops. Continuous or intermittent mixing is used in this type of operating system due to the floating bark and the sludge arising in the fermentation space. [1] Of the batch reactor units of the research laboratory, the most professional are the three Fermac 320 5-litre bioreactors (Figure 1).

The units are fully automated, controlled by remote access, logging the $\mathrm{pH}$ change, temperature and mixing parameters. Their use is not preferred because it is unsuitable for mixing or homogenising the experimental base material (vegetation) with the factory mixing blades.

Based on this, we have set the design and implementation of a unique horizontal reactor based on the automated properties of Fermac. The operation of the planned and manufactured equipment was verified by an empirical and comparative method.

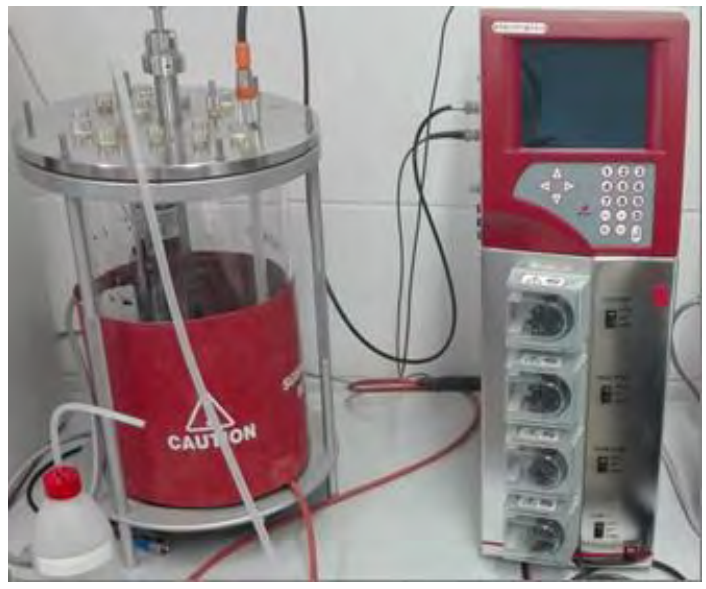

Figure 1. Units of Fermac 320

\section{Mixing in the bioreactor}

The essence of the mixing is to not allow settling of the dry matter in the fluid medium, to homogenize the medium and to intensify the biological processes. Thus, the bacteria responsible for the gas production have a larger surface available, and more biogas is formed.

A batch experiment was conducted at the Environment and Power Engineering faculty of the Technical University of Denmark at $55^{\circ} \mathrm{C}$ with the 
intensity of mixing (minimal, weak, powerful). It has been shown that if the system is overloaded (too high substrate content), minimal mixing is the most effective. For a continuous system, the minimum mixing time was 10 minutes before feeding. [2]

The mechanical mixing of bioreactors is the most common method in industrial scale. Vertical Flatbed Mixers (Rushton) are used primarily for high-speed mixing. This is ideal for blending bacterial cultures but is less effective when mixing plant cells. The Fermac 320 system is also equipped with this. When mixing vegetable waste the use of different inclination propellers is more efficient - axial mixing is also achievable. [3]

\section{Horizontal Reactor Designs}

In one type of horizontal drum reactor, the drum structure acts as the reactor body itself rotates. The attached blades and lifting buckets produce the required mixing and the drum is rotated by rollers driven by electric motors.

The second group includes reactors with fixed tanks and some mixing equipment operating in their interior. For laboratory-sized equipment, a variety of mixers can be found. Industrial sizes generally work with axial spiral stirrers or snail mixers. The mixing of tank-type reactors is generally continuous.

\section{Designing a horizontal mixing bio- reactor}

The goal was to design an interior agitated reactor with a fixed body based on literature research and labour requirements. During construction, we used the Fermac 320's multiple parameters and components to make the new system compatible with a commercially available unit. Not only internal volume but also physical dimensions, such as outer, inner diameter and height (when lying the length) are also the same. The most important component of the reactor is the body itself. The factory units are made of tempered glass. For fermentation of organic matter, this is not ideal, because one of the basic conditions for optimum biogas formation is to shield bacteria from light.

Each element of the designed reactor is made of corrosion-resistant steel. The 5-litre reactor body with operating volume consists of three parts. The core element is a stainless steel tube with a wall thickness of $3.5 \mathrm{~mm}$. Holed flanges are welded to both sides. The rotation of the cylindrical reactor body is blocked by the foot. This is a rubber inner tube clamp to which M8 nuts are welded. With the appropriate length of screws, the angle of the reactor can be adjusted relative to the horizontal. In the experiment, the reactor was in a horizontal position.

The other side of the fermentation unit is covered with a plexi plate. The Plexiglas plate is glued to the edge with a polysilox-ane-based sealant and then fixed with screws at its final position. With this Plexiglas plate, an insight can be gained into the reactor during operation and using a variety of illustrative materials, to provide a suitable demonstration tool for students who are studying or working in the laboratory.

Another main element of the reactor is the mixer. The task of this unit is to prevent sludge deposition, sedimentation and the solubility of the dry matter added to the system.

A milling wheel-like design was chosen, which is capable of mixing the fluid inside the reactor with almost the entire length of the reactor. The mixer is designed with six shovels positioned $60^{\circ}$ apart. The mixer is made of corrosion-resistant steel of $1 \mathrm{~mm}$ thickness.

The blades are held in place by four rings and one end disk. The outer diameter of the mixer is only $5 \mathrm{~mm}$ smaller than the inside diameter of the reactor to allow it to move as much as possible of the dry matter deposited on the bottom of the reactor. The fixing point is positioned as close as possible to the temperature probe, thus reducing axle bend.

The mixer plate model is shown in Figure 2.a, the layout with the lid and the probe shown in Figure 2.b, and the model of the assembled unit in Figure 2.c.
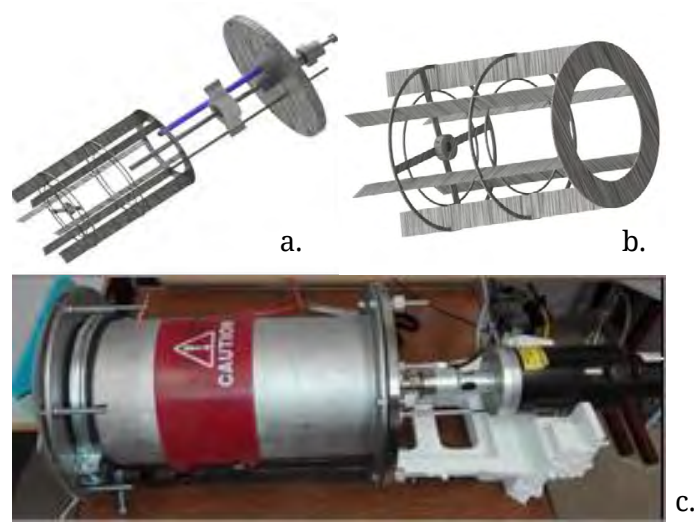

Figure 2. The mixer model and the completed unit 
Several elements of Fermac were used for the reactor. The most important such unit being the lid. It incorporates the reactor axle which is both bearings and insulated so no liquid or gas leakage occurs while stirring. This element contains the location of the $\mathrm{pH}$ probe and the temperature meter is also located here. The constant speed of the mixer is ensured by an electric motor fixed at the end of the axle which is adjusted via the control unit.

The heating is provided with an electric resistance heating cap attached to the reactor wall. The reactor was run on continuous logging. During each experiment, simultaneous comparative testing was initiated at the same time in the planned and factory reactor.

\section{The results of the control experi- ment}

In the experiments, a ferment broth from a South-Pest wastewater treatment plant was used as a seeding sludge. The experimental raw material was a wheat straw fraction of less than $2 \mathrm{~mm}$ in length. The fermentation was carried out according to VDI 6430 Organic Substances Fermentation Directive [4]. Logged values are monitored throughout the experiment. The set mixing value was $10 \mathrm{rpm}$ for the designed and factory reactor. [5].

During the experiment, there was a great difference between the two reactors during the temperature change. The glass heats faster and exchanges heat with the liquid, but unfortunately overheats the system in relation to the preset value. It warms up to approximately $42-44^{\circ} \mathrm{C}$, which is no longer within the mesophilic range. Thereafter, a cooling section is displayed, which stabilizes at a good approximation at $37{ }^{\circ} \mathrm{C}$. It took about 5 hours to reach $37^{\circ} \mathrm{C}$. Further constant fluctuations are seen in the factory reactor temperature diagram as the glass quickly loses the heat. Therefore, the heating jacket is switched on and off 2-3 times per hour. Each time it switches on, it overheats the system at $1-2{ }^{\circ} \mathrm{C}$ before it switches off and only switches on again when the liquid has cooled to $35-36{ }^{\circ} \mathrm{C}$. There is no overheating stage for the metal body reactor. The temperature fluctuation observed here is only $0.3{ }^{\circ} \mathrm{C}$ in positive and negative directions compared to the set value.

The mixer of the intended fermentation unit performed this job perfectly. The cumulated gas flow of the horizontal reactor increased by $54 \%$ and the cumulative methane yield by $64 \%$ higher than the vertical unit. (Figure 3.)

\section{Conclusions}

During the experiment, it has been proven that the reactor designed by us functions well when feeding vegetable raw material with greater grain size. Maintaining the temperature, successful homogenization of the raw material, all achieved the expected result: a stable and high gas yield. It can be said that the planned horizontal bioreactor is a laboratory bioreactor suitable for anaerobic digestion under laboratory conditions.

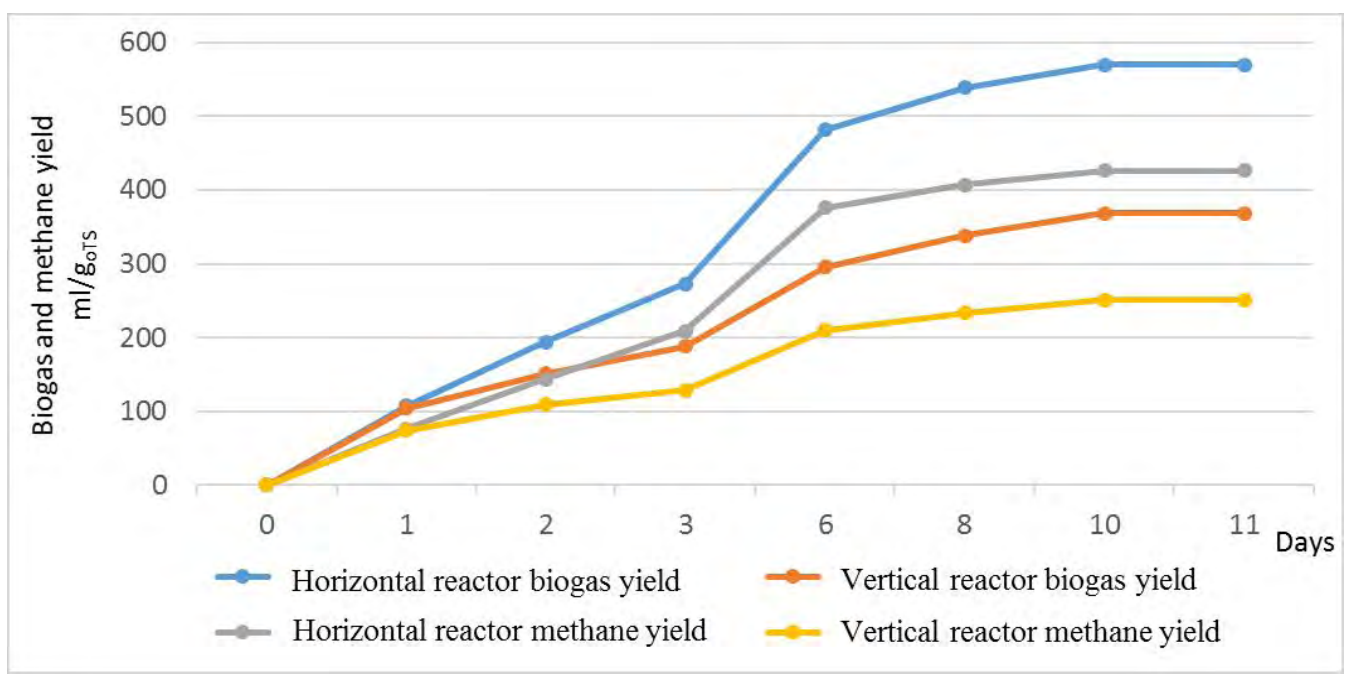

Figure 3. Cumulative biogas and methane yield curves 


\section{Acknowledgement}

The research was performed with the help of Ádám Misi, with using the equipment of the biomass preparing laboratory at Óbuda University. "Supported by the ÚNKP-17-4 New National Excellence Program of the Ministry of Human Capacities”.

\section{References}

[1] Dr. Czupy Imre, Vágvölgyi Andrea: Mezőgazdasági (növénytermesztés, állattartás, erdészeti) hulladékok kezelése és hasznositása.

http://www.tankonyvtar.hu/hu/tartalom/tamop425/0021_Mezogazdasag_hulladekai/ch04s05. html

[2] Prasad Kaparaju, Inmaculada Buendia, Lars Ellegaard, Irini Angelidakia: EDects of mixing on methane production during thermophilic anaero- bic digestion of manure: Lab-scale and pilot-scale studies. Bioresource Technology 99/11. (2008) 4919-4928

https://doi.org/10.1016/j.biortech.2007.09.015

[3] Biologydiscussion.com, Parul Kumar: Top 3 Types of Bioreactors.

http://www.biologydiscussion.com/bioreactors/bioreactors-types-top-3-types-of-bioreactors/12213

[4] VDI 4630 - Fermentation of organic materials characterisation of the substrate, sampling, collection of material data, fermentation tests. Verein Deutscher Ingenieure Handbuch, Energietechnik. 44-59. Düsseldorf, 2006

[5] Electrolab Biotech Limited. FerMac 320 bioreactor fermenter (2015)

https://www.electrolabtech.co.uk/Bioreactor_ Fermenters/Fermac_320.aspx 